\title{
Telomerase activity and hTERT mRNA expression in glial tumors
}

\author{
L. BOLDRINI ${ }^{1}$, S. PISTOLESI ${ }^{1}$, S. GISFREDI ${ }^{1}$, S. URSINO ${ }^{1}$, G. ALì ${ }^{1}$, N. PIERACCI ${ }^{2}$, \\ F. BASOLO ${ }^{1}$, G. PARENTI ${ }^{2}$ and G. FONTANINI ${ }^{1}$ \\ Departments of ${ }^{1}$ Surgery, and ${ }^{2}$ Neuroscience, University of Pisa, I-56100 Pisa, Italy
}

Received December 12, 2005; Accepted February 7, 2006

\begin{abstract}
Human telomerase is a structurally complex ribonucleoprotein that is responsible for the maintenance of telomeric DNA at the ends of the chromosomes. The enzyme is proposed as having an important role in cell immortalization and oncogenesis. A limited number of studies have been performed on the telomerase system in brain tumors, and these studies are somewhat conflicting. The relative ineffectiveness of current therapies for malignant gliomas led to the need for novel targets for more promising approaches. In order to clarify the prognostic significance of telomerase expression in gliomas and to speculate on therapeutic implications, we examined telomerase activity by the telomeric repeat amplification protocol (TRAP) assay in 42 gliomas, (32 multiform glioblastomas, 4 anaplastic astrocytomas, 4 differentiated astrocytomas, 1 oligoastrocytoma and 1 oligosarcoma). Telomerase messenger expression (hTERT mRNA) was evaluated by reverse transcription-PCR analysis in the same group of tumors. High telomerase activity was detected in 21/42 gliomas (50\%). The levels of telomerase in terms of its messenger level expression overlapped the activity; in fact, a significant association between telomerase activity and hTERT mRNA expression was found $\left(\chi^{2}\right.$ test; $\mathrm{p}<0.0001)$. At univariate analysis, advanced age as well as high telomerase activity and hTERT mRNA levels were seen to be significant predictors of worse prognosis regarding both overall survival $(\mathrm{p}=0.007, \mathrm{p}=0.007, \mathrm{p}=0.04$, respectively) and disease-free interval ( $\mathrm{p}=0.008, \mathrm{p}=0.008, \mathrm{p}=0.04$, respectively). All these variables maintained a significant independent prognostic role in multivariate analysis. Telomerase may represent an indicator of progression and poor prognosis in this type of cancer, with interesting therapeutic implications.
\end{abstract}

\section{Introduction}

Human telomerase is a structurally complex ribonucleoprotein that is responsible for the maintenance of telomeric DNA at

Correspondence to: Professor Gabriella Fontanini, Department of Surgery, University of Pisa, via Roma 57, I-56100 Pisa, Italy

E-mail: g.fontanini@med.unipi.it

Key words: telomerase activity, hTERT mRNA, gliomas the ends of the chromosomes. Telomerase acts to synthesize and add a simple six-base motif (of TTAGGG in human cases) to the ends of the chromosomes, resulting in stable telomere length that would otherwise be gradually eroded after each cell replication (1-3). The enzyme is proposed to have an important role in cell immortalization and oncogenesis (4). Active telomerase has been detected in a majority of human cancers and in embryonic and germline cells but not in normal somatic cells, with the exception of some stem cells, such as those involved in tissue renewal. The grade and stage at which telomerase is expressed for each given tumor type are variable (5-10).

A limited number of studies have been performed on the telomerase system in brain tumors (11-16) and are somewhat conflicting (17-20). Little is known concerning the clinical significance of telomerase expression in the pathogenesis and progression of intracranial neoplasms; high levels of telomerase seem to be associated with a poor outcome in neuroblastomas (21), astrocytomas (22) and high-grade gliomas $(23,24)$.

In this study, we quantified the telomerase activity of 42 gliomas using the polymerase chain reaction (PCR)-based telomeric repeat amplification protocol (TRAP) assay. We also compared these results with the expression of the messenger coding the telomerase catalytic subunit (hTERT mRNA). The goal of this work was to expand the present knowledge of telomerase activity in brain tumors, in order to clearly assess whether telomerase may be a novel prognostic marker for brain tumors with a high grade of malignancy, such as glioblastomas.

\section{Materials and methods}

Surgical specimens. The study base was a consecutive series of 42 patients, who had undergone total surgical resection of glial tumors (32 multiform glioblastomas, 4 anaplastic astrocytomas, 4 differentiated astrocytomas, 1 oligoastrocytoma and 1 oligosarcoma) at the U.O. of Neurosurgery, University of Pisa, from 2001 to 2005 . There were 24 male patients and 18 female patients (mean age, 60.85 years; median, 63 years, range, 28-79 years). The pathologists, based on the criteria of the World Health Organization (WHO) $(25,26)$ performed the classification and grading of the tumors. According to tumor grade, there were 4 Grade II $(9.5 \%), 5$ Grade III (11.9\%), and 33 Grade IV (78.6\%). Data on clinical behavior were available 
in all of the 42 cases (median follow-up, 29 months; mean, 29.9; range, 5-52). Fourteen patients were alive at the time of analysis and twelve patients had relapsed, in spite of complete surgical resection, as confirmed by pre- and postoperative computerized axial tomographies (TAC).

Cases were enrolled after surgical removal of the lesion and pathological confirmation but prior to radiation therapy. Tumor samples, obtained at surgery, were partly paraffinembedded for histological processing and partly immediately frozen in liquid nitrogen. Because contamination from lymphocyte infiltration in the tissue may account for a false-positive telomerase, a histological review of all the samples was performed.

Telomerase assay. The development of a sensitive and efficient PCR-based telomerase activity detection method, TRAP (Telomeric Repeat Amplification Protocol) (27), has made possible large-scale surveys of telomerase activity in human cells and tissue. The TRAPeze ${ }^{\circledR} \mathrm{Kit}$ is a highly sensitive in vitro assay system for detecting telomerase activity. The methodology used in the TRAPezeTelomerase detection kit is based on a one buffer-two enzyme assay using polymerase chain reaction (PCR). In the first step of the reaction, telomerase adds a number of telomeric repeats (GGTTAG) onto the 3 ' end of a substrate oligonucleotide (TS). In the second step, the extended products are amplified by PCR using the TS and RP (reverse) primers, generating a ladder of products with 6 base increments starting at 50 nucleotides: 50, 56, 62, 68, etc. Additionally, each reaction mixture contains a primer (K1) and a template (TSK1) for amplification of a 36-bp internal standard. Incorporation of this internal positive control makes it possible to quantify telomerase activity more accurately and to identify false-negative samples that contain Taq polymerase inhibitors.

The TRAP assay measures telomerase activity in sample lysates by telomerase-mediated extension of the TS oligonucleotide, followed by amplification, electrophoresis and visualization of extended products. A TRAP assay is considered valid when all of the following conditions are met: no visible product, except the 36-bp internal control band, in the negative control; the 36-bp internal control band and a ladder of products with 6-bp TTAGGG repeats on the TS oligonucleotide, producing a 6-base incremental ladder of TRAP products, in the positive control; and no visible product in heat-treated samples, except the 36-bp internal control band.

Telomerase positive samples showed an identical pattern to the positive control, while samples without telomerase activity did not display this characteristic ladder.

To obtain valid quantitative values of telomerase activity using the TRAP assay, we included a quantity control template TSR8. Using a CCD imaging system and image analysis program, we evaluated the densitometric signal of the gel lane corresponding to the TRAP product ladder bands from all samples, including non-heat-treated $(\mathrm{x})$ and heat-treated sample extracts $\left(\mathrm{x}_{0}\right)$, negative control $\left(\mathrm{r}_{0}\right)$, and TSR 8 quantity control (r). We also evaluated the signal from the internal standard in non-heat-treated samples (c) and TSR8 quantity control $\left(\mathrm{c}_{0}\right)$. The amount of telomerase product was quantified using the following formula: TPG (units) $=\left(\mathrm{x}-\mathrm{x}_{0}\right) / \mathrm{c} \mid\left(\mathrm{r}-\mathrm{r}_{0}\right) /$ cr x 100 (if 0.1 amole of TSR8 is used).
Each unit of TPG (total product generated) corresponds to the number of TS primers (in $1 \times 10^{-3}$ amole or 600 molecules) extended with at least 4 telomeric repeats by telomerase in the extract in a 10 -min incubation at $30^{\circ} \mathrm{C}$. The assay has a linear range of 1-300 TPG, which is equivalent to telomerase activity from approximately 30-10000 control cells.

PCR analysis of hTERT. Total RNA was extracted from normal and neoplastic frozen tissues, and was primed with random hexamers to synthesize complementary DNA (cDNA) using AMV reverse transcriptase. PCR was carried out in a PerkinElmer Thermal Cycler, as described above (28). To examine hTERT mRNA expression in detail, we performed RT-PCR using primers for the reverse transcriptase domain of the transcript (TERT-2164S and TERT-2620A). The full-length product was $457 \mathrm{bp}$. Two potential splice sites are within the region spanned by this primer set: the first splice site determines a 36-bp deletion ( $\alpha$ deletion; bases 2186-2221) with consequent inactivation of reverse transcriptase. The second splice site causes a 182-bp deletion ( $\alpha+\beta$ deletion; bases 2342-2524) resulting in a nonsense mutation, encoding a truncated protein lacking vital reverse transcriptase motifs.

The hTERT cDNA amplification used TERT-2164S (GCCTGAGCTGTACTTTGTCAA) and TERT-2620A (CGCAAACAGCTTGTTCTCCATTACTTTGTCAA) oligonucleotides with an initial heating at $94^{\circ} \mathrm{C}$ for $90 \mathrm{sec}$, followed by 35 cycles at $95^{\circ} \mathrm{C}$ for $25 \mathrm{sec}, 68^{\circ} \mathrm{C}$ for $50 \mathrm{sec}$, and $72^{\circ} \mathrm{C}$ for $50 \mathrm{sec}$.

The presence of a 412 PCR band amplified with specific primers for GAPDH with the same cDNA was used as an internal control. PCR primers for GAPDH cDNA were as follows: forward primer, 5'-CGATGCTGGCGCTGAGTAC-3'; reverse primer, 5'-CGTTCAGCTCAGGGATGACC-3' (29). The amplification products were separated on $1.5 \%$ agarose gels and visualized by ethidium-bromide staining. No band is detected when no cDNA is added to the PCR mixture. We calculated the ratio between hTERT and GAPDH densitometric values as relative hTERT mRNA expression.

Statistical analysis. All statistical analyses were carried out using Statistica software (Stat-soft). A $\chi^{2}$ test was used to analyze the associations between the different variables. Survival was calculated from the time of the initial operation until the patient died or until the final analysis. Survival rates were determined by the Kaplan-Meier method and differences were analysed by the Cox-F test. Multivariate analysis was carried out using the Cox proportional-hazard model. The a priori level of significance was set at $\mathrm{p}<0.05$.

\section{Results}

Clinico-pathological features. The clinico-pathological features of brain tumors are given in Table I. The prognostic importance of age, sex, grade, relapse and histotype was studied. The median age of the patients was 63 years; 22 patients were $<63$ years. Younger age was associated with a significantly better prognosis $(\mathrm{p}=0.01$ for overall survival and $\mathrm{p}=0.012$ for disease-free interval); thus, age was included in the multivariate model. No statistical significance was found for sex, grade, relapse and histotype. 
Table I. Univariate survival analysis.

\begin{tabular}{|c|c|c|}
\hline Features & $\begin{array}{c}\text { No. of } \\
\text { patients }\end{array}$ & $\begin{array}{cc}\text { Overall } & \text { Disease-free } \\
\text { survival } & \text { interval } \\
(\mathrm{P}-\mathrm{value}) & (\mathrm{P} \text {-value })\end{array}$ \\
\hline
\end{tabular}

\section{Sex}

Male

Female

\section{4}

18

0.228

0.18

Age (years)

$\leq 63$

$>63$

20

0.01

0.012

Tumor grade

II

III

IV

4

5

33

Relapse

Yes

No

0.505

0.349

Histotype

Glioblastoma

Differentiated astrocytoma

Anaplastic astrocytoma

Oligoastrocytoma

Gliosarcoma

Telomerase activity

Low

High

21

21

0.007

0.008

Telomerase mRNA

$\begin{array}{lrrr}\text { Low } & 26 & \mathbf{0 . 0 4 6} & \mathbf{0 . 0 4 6} \\ \text { High } & 13 & & \end{array}$

Bold type, statistically significant, $<0.05$.

Telomerase activity. In the present study, telomerase-positive extracts produced a characteristic 6-bp ladder. An extract was considered positive for telomerase activity when a 36-bp internal control band and a ladder of PCR produced with 6 base increments, similar to that of the telomerase-positive control lane, were present (Fig. 1A). By normalizing the signal intensity of the telomerase ladder to that of the internal control, sample-to-sample variation due to PCR amplification efficiency was minimized, thus allowing for semi-quantitative analysis. Levels of telomerase activity were expressed as TPG units: the mean \pm SD of the TPG units was $13.9 \pm 9.1$, while the median value was 14 TPG units.

The median value was assumed as the cut-off value to distinguish gliomas with low from those with high telomerase activity. High telomerase activity was detected in 21/42 glial tumors $(50 \%)$; the presence of polymerase chain reaction or Taq inhibitors in negative TRAP reactions seems unlikely, because negative extracts retested at higher diluitions remained negative. No significant difference was found between telomerase levels in low-grade gliomas (II and III) in comparison to high grade.

We also analyzed the survival time of our glioma patients, comparing the two groups with low and high telomerase. A
A

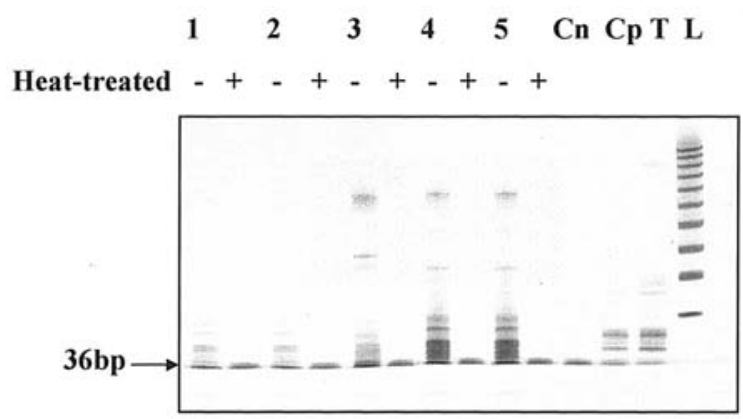

$\begin{array}{lllllll}1 & 2 & 3 & 4 & 5 & \mathrm{Cn} & \mathrm{L}\end{array}$

B

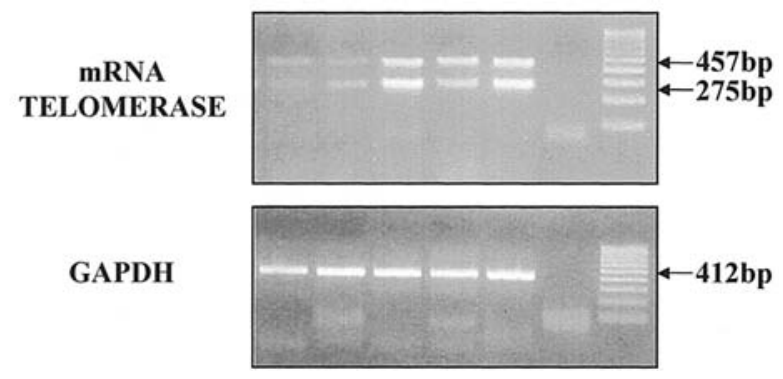

Figure 1. A, telomerase activity in glial tumors. Lanes 1 and 2, samples displayed a low level of telomerase activity; lanes 3-5, samples with a high level of telomerase activity; $\mathrm{Cn}$, negative control with no lysate added; $\mathrm{Cp}$, positive control, telomerase positive cells $\left(10^{6}\right.$ cells $)$; T, TSR8, quantitation control template; L, molecular weight marker (100-bp ladder, Pharmacia); + , heat inactivation of telomerase; -, without heat pretreatment. B, telomerase mRNA expression in glial tumors. Lanes 1 and 2, samples displayed a low level of hTERT mRNA; lanes 3-5, samples with a high level of hTERT mRNA; Cn, negative control; L, molecular weight marker (100-bp ladder, Pharmacia). The 457-bp band corresponds to full-length product; $275 \mathrm{bp}$ is one splice variant $(\alpha+\beta$ deletion). In the lower panel, amplification of the housekeeping GAPDH gene (412 bp) in the same samples is shown.

significant difference in overall survival as well as in diseasefree interval was found between patients with low telomerase and those with high; that is, the survival time of patients with high telomerase activity was shorter than that of those with low telomerase (Fig. 2).

Expression of hTERT $m R N A$. Final quantified telomerase messenger levels were expressed as a ratio to GAPDH expression. Fig. 1B shows an example of RT-PCR analysis of hTERT messenger in gliomas. Based on evidence that only full-length hTERT transcripts code an active reverse transcriptase and that no telomerase activity is expressed without full-length hTERT message, we considered our samples as positive and then quantified telomerase expression when the full-length product was detected.

Assuming a median value of 0.75 (mean $0.73 \pm 0.77$ ) for relative telomerase expression as the cut-off value, we distinguished gliomas with low from those with high hTERT messenger levels. High hTERT mRNA levels were found in $13 / 39(33.3 \%)$ of glial tumors (for three samples, not enough tissue was available). A significant correlation between telomerase mRNA and enzyme activity levels was found $\left(\chi^{2}\right.$ test; $\left.\mathrm{p}<0.0001\right)$.

The analysis by RT-PCR revealed high levels of hTERT expression in tumors with worse overall survival and disease- 

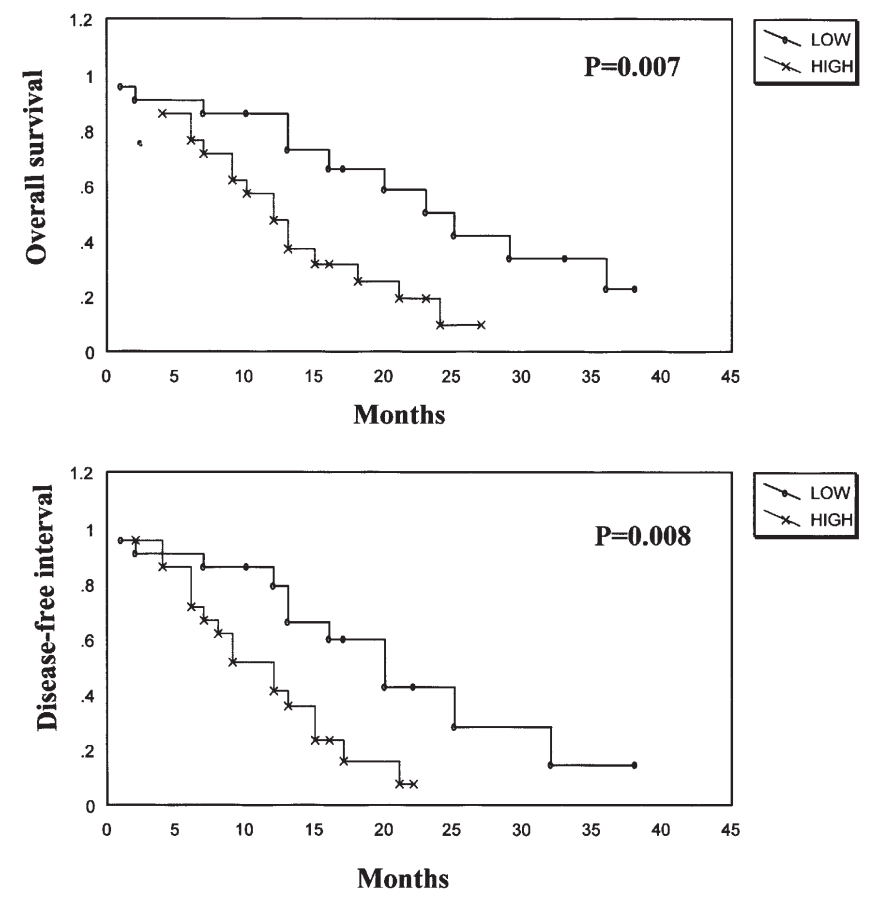

Figure 2. Kaplan-Meier overall survival and disease-free interval curves in relation to telomerase activity levels in glial tumors.
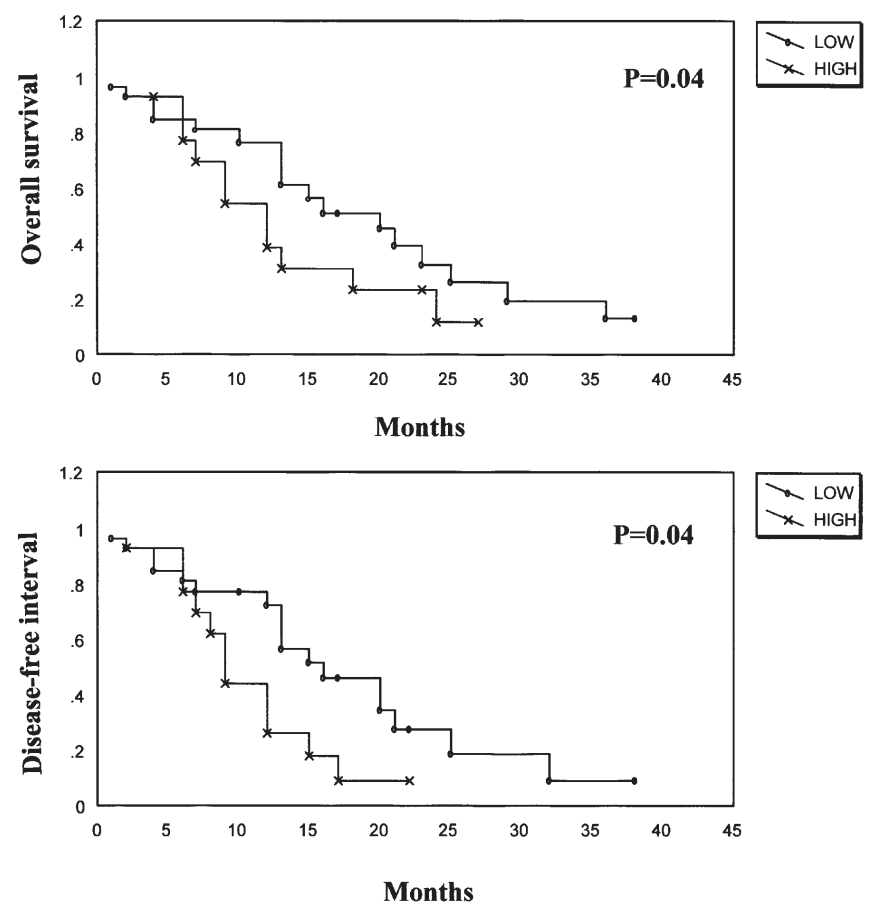

Figure 3. Kaplan-Meier overall survival and disease-free interval curves in relation to hTERT mRNA levels in glial tumors.

free interval, confirming a prognostic role also for telomerase messenger, as shown in Fig. 3.

Multivariate analysis. All the variables that significantly affected survival in univariate analysis maintained their independent prognostic influence on overall survival in a Cox proportional-hazard model $(\mathrm{p}=0.023$ for younger age;
Table II. Cox proportional-hazard model of overall survival.

\begin{tabular}{lcccc}
\hline Variables & Beta & Standard error & $\mathrm{t}$ & P-value \\
\hline Sex & 0.2835 & 0.4988 & 4.131 & $\mathbf{0 . 0 2 3}$ \\
Telomerase activity & 0.7413 & 0.3491 & 1.239 & $\mathbf{0 . 0 1 2}$ \\
Telomerase mRNA & 0.7258 & 0.3374 & 1.639 & $\mathbf{0 . 0 1}$ \\
\hline
\end{tabular}

$\mathrm{p}=0.012$ for low telomerase activity and $\mathrm{p}=0.01$ for low hTERT mRNA) (Table II).

\section{Discussion}

Telomerase expression and on-going activity are generally accepted to be paramount to the survival and proliferation of the majority of cancer cells (30). Telomerase expression occurs in the later phases of multistep tumor progression of some classes of tumors (31), and is especially characteristic of higher-grade neoplasms.

Our present study confirmed the frequency observed by several investigators (telomerase expression in $26-89 \%$ of multiform glioblastoma) (32-38). However, the studies of Langford et al (17), De Masters et al (18) and Nakatani et al (19) agreed with our data that a percentage of multiform glioblastomas and anaplastic astrocytomas were negative or at low-level for telomerase expression, a paradoxical finding in light of their high degree of malignancy and in contrast to the almost uniform telomerase positivity of high-grade systemic tumors. Multiform glioblastomas are highly heterogeneous tumors, and this variability might influence telomerase expression.

Moreover, alternative mechanisms to stabilize telomeres may be present. Recently, alternative lengthening of telomeres (ALT) was found to be a prognostic indicator for patients with multiform glioblastoma and, in patients with non-ALT tumors, telomerase activity did not affect survival (39).

In our cases, clinical follow-up was available for all patients. Univariate analysis revealed age as a significant prognostic factor, with consensus in the current literature $(40,41)$. Moreover, we found a shorter survival time (both in terms of overall survival and of disease-free interval) in patients whose tumors showed high telomerase activity in comparison with tumors showing low telomerase activity. We did not find a relationship between telomerase activity and the grade of the glial tumors; this is probably due to the great number of grade IV gliomas in our series $(33 / 42,78.6 \%)$.

We analyzed hTERT expression in the same samples; we detected only full-length and $\alpha+\beta$ deleted isoforms, as we had previously found in colorectal cancer (42), in meningiomas (16) and in skin cancer samples (43). A significant correlation between levels of telomerase activity and its messenger expression was also found, even if a few cases of high-grade tumors showed a discrepancy in the presence of elevated telomerase activity and low/undetectable hTERT mRNA levels. The heterogeneous nature of glioblastomas and astrocytomas might yield variability in the results concerning hTERT mRNA expression, as was previously discussed regarding telomerase 
activity. Alternatively, it is possible that differences between the half-life of telomerase catalytic protein and its messenger $(30,44)$, or interactions between telomerase messenger and regulatory proteins, exist; in this respect, the escape from molecular detection of hTERT mRNA could explain the absence of the messenger in telomerase-positive tumors (45-47). Overall survival rates were significantly worse in tumors with high hTERT expression and those with telomerase activity.

In conclusion, the overall picture emerging from our study is that telomerase activity may influence tumor prognosis in gliomas. Recently, specific inhibitors of telomerase have been used as potential anticancer agents, but only in cell lines and xenografts (48-50). Our results, with further elucidations on telomerase involvement in the mechanisms of tumor angiogenesis, apoptotic pathway and telomere elongation, may encourage research on novel therapeutic strategies for the treatment of patients with malignant gliomas.

\section{Acknowledgements}

This work has been supported by grants from the Associazione Italiana per la Ricerca sul Cancro (A.I.R.C.).

\section{References}

1. Blackbun FH: Structure and function of telomeres. Nature 350: 569-573, 1991.

2. Greider CW: Telomere length regulation. Annu Rev Biochem 65: 337-365, 1996.

3. McEachern MJ, Krauskopf and Blackburn EH: Telomeres and their control. Annu Rev Genet 34: 331-358, 2000.

4. Shay JW and Bacchetti S: A survey of telomerase activity in human cancer. Eur J Cancer 33: 787-791, 1997.

5. Chadeneau C, Hay K, Hirte HW, Gallinger S and Bacchetti S: Telomerase activity associated with acquisition of malignancy in human colorectal cancer. Cancer Res 55: 2533-2536, 1995.

6. Tahara H, Nakanishi T, Kitamoto M, et al: Telomerase activity in human liver tissues: comparison between chronic liver disease and hepatocellular carcinomas. Cancer Res 55: 2734-2736, 1995.

7. Hiyama K, Hiyama E, Ishioka S, et al: Telomerase activity in small-cell and non-small-cell lung cancers. J Natl Cancer Inst 87: 895-902, 1995.

8. Hiyama E, Okayama T, Tatsumoto N, et al: Telomerase activity in gastric cancer. Cancer Res 55: 3258-3262, 1995.

9. Sommerfeld HJ, Meeker AK, Piatyszek MA, Bova GS, Shay JW and Coffey DS: Telomerase activity: a prevalent marker of malignant human prostate tissue. Cancer Res 56: 218-222, 1996.

10. Hiyama E, Gollahan L, Kataoka T, et al: Telomerase activity in human breast tumors. J Natl Cancer Inst 88: 116-122, 1996.

11. Sallinen P, Miettinem H, Sallinem SL, Haapasalo H, Helin H and Kononem $\mathrm{J}$ : Increased expression of telomerase RNA component is associated with increased cell proliferation in human astrocytomas. Am J Pathol 150: 1159-1164, 1997.

12. Falchetti ML, Pallini R, Larocca LM, Verna R and D'Ambrosio E: Telomerase expression in intracranial tumors: prognostic potential for malignant gliomas and meningiomas. J Clin Pathol 52: 234-236, 1999.

13. Grzybicki DM and Moore SA: Implications of prognostic markers in brain tumors. Clin Lab Med 19: 833-847, 1999.

14. Chen HJ, Liang CL, Kang L, Lin JW and Cho CL: Implication of telomerase activity and alterations of telomere length in the histologic characteristics of intracranial meningiomas. Cancer 89: 2092-2098, 2000

15. Cabuy E and De Ridder L: Telomerase activity and expression of telomerase reverse transcriptase correlated with cell proliferation in meningiomas and brain tumors in vivo. Virchows Arch 439: 176-184, 2001.

16. Boldrini L, Pistolesi S, Gisfredi S, et al: Telomerase in intracranial meningiomas. Int J Mol Med 12: 943-947, 2003.
17. Langford LA, Piatyszek MA, Xu R, Schold SC Jr and Shay JW Telomerase activity in human brain tumors. Lancet 346 : 1267-1268, 1995.

18. De Masters BK, Markham N, Lillehei KO and Shroyer KP: Differential telomerase expression in human primary intracranial tumors. Am J Pathol 107: 548-554, 1997.

19. Nakatani K, Yoshimi N, Mori H, Yoshimura S, Sakai H, Shinoda J and Sakai N: The significant role of telomerase activity in human brain tumor. Cancer 80: 471-476, 1997.

20. Kleinschmidt BK-De Masters, Hashizumi TL, Sze CI, Lillehei KO, Shroyer AL and Shroyer KR: Telomerase expression shows differences across multiple regions of oligodendroglioma versus high grade astrocytomas but shows correlation with Mib-1 labelling. J Clin Pathol 51: 284-293, 1998.

21. Hiyama E, Hiyama K, Yokoyama T, Matsuura Y, Piatyszek MA and Shay JW: Correlating telomerase activity levels with human neuroblastoma outcomes. Nat Med 1: 249-255, 1995

22. Fukushima T, Yoshino A, Katayama Y, Watanabe T, Kusama K and Moro I: Prediction of clinical course of diffusely infiltrating astrocytomas from telomerase expression and quantitated activity level. Cancer Lett 187: 191-198, 2002.

23. Huang F, Kanno H, Yamamoto I, Lin Y and Kubota Y: Correlation of clinical features and telomerase activity in human gliomas. J Neurooncol 43: 137-142, 1999.

24. Tchirkov A, Rolhion C, Kemeny J-L, et al: Clinical implication of quantitative real-time RT-PCR analysis of hTERT gene expression in human gliomas. Br J Cancer 88: 516-520, 2003.

25. Louis DN: Meningiomas. In: Pathology and Genetics of tumors of the Nervous System. Kleihues P and Cavanee WK (eds). IARC press, Lyon, pp176-184, 2000.

26. Kleihues P, Louis DN, Scheithauer BW, Rorke LB, Reifenberger G, Burger PC and Cavanee WK: The WHO classification of tumors of the nervous system. J Neuropathol Exp Neurol 61: 215-225, 2002.

27. Wright WE, Shay JW and Piatyszek MA: Modifications of a telomeric repeat amplification protocol (TRAP) result in increased reliability, linearity and sensitivity. Nucleic Acids Res 23: 3794-3795, 1995.

28. Ulaner GA, Hu J-F, Vu TH, Giudice LC and Hoffman AR: Telomerase activity in human development is regulated by human telomerase reverse transcriptase (hTERT) transcription and by alternate splicing of hTERT transcripts. Cancer Res 58: 4168-4172, 1998.

29. Wizigmann-Voos S, Breier G, Risau W and Plate KH: Upregulation of vascular endothelial growth factor and its receptors in von Hippel-Lindau disease-associated and sporadic hemangioblastomas. Cancer Res 55: 1358-1364, 1995.

30. Holt SE, Aisner DL, Shay JW and Wright WE: Lack of cell cycle regulation of telomerase activity in human cells. Proc Natl Acad Sci USA 94: 10687-10692, 1997.

31. Blasco MA, Rizen M, Greider CW, et al: Differential regulation of telomerase activity and telomerase RNA during multi-stage tumorigenesis. Nat Genet 12: 200-204, 1996.

32. Kim NW, Piatyszek MA, Prowse KR, et al: Specific association of human telomerase activity with immortal cells and cancer. Science 266: 2011-2015, 1994.

33. Morii K, Tanaka R, Onda K, Tsumanuma I and Yoshimura J: Expression of telomerase RNA, telomerase activity, and telomere length in human gliomas. Biochem Biophys Res Commun 239: 830-834, 1997.

34. Chong EY, Lam PY, Poon WS and Ng HK: Telomerase expression in gliomas including the non-astrocytic tumors. Hum Pathol 29: 599-603, 1998.

35. Hiraga S, Ohnishi T, Izumoto S, Miyahara E, Kanemura Y, Matsumura $\mathrm{H}$ and Arita $\mathrm{N}$ : Telomerase activity and alterations in telomere length in human brain tumor. Cancer Res 58: 2117-2125, 1998 .

36. Simon M, Park T-W, Leuenroth S, Hans VHJ, Loning T and Schramm J: Telomerase activity and expression of the telomerase catalytic subunit, hTERT, in meningioma progression. J Neurosurg 92: 832-840, 2000.

37. Le S, Zhu JJ, Anthony DC, Greider CW and Black PM: Telomerase activity in human gliomas. Neurosurgery 42: 1120-1125, 1998.

38. Sano T, Asai A, Mishima K, Fujimaki T and Kirino T: Telomerase activity in 144 brain tumors. Br J Cancer 77: 1633-1637, 1998.

39. Hakin-Smith V, Jellinek DA, Levy D, et al: Alternative lengthening of telomeres and survival in patients with glioblastoma multiform. Lancet 361: 836-838, 2003. 
40. Ozbek N, Cakir S, Gursel B and Meydan D: Prognostic significance of seizure in patients with glioblastoma multiform. Neurol India 52: 76-78, 2004.

41. Batchelor TT, Betensky RA, Esposito JM, et al: Age-dependent prognostic effects of genetic alterations in glioblastoma. Clin Cancer Res 10: 228-233, 2004.

42. Boldrini L, Faviana P, Gisfredi S, et al: Evaluation of telomerase mRNA (hTERT) in colon cancer. Int J Oncol 21: 493-449, 2002.

43. Boldrini L, Loggini B, Gisfredi S, et al: Evaluation of telomerase in non-melanoma skin cancer. Int J Mol Med 11: 607-611, 2003.

44. Xu D, Gruber A, Bjorkholm M, Peterson C and Pisa P: Suppression of telomerase reverse transcriptase (hTERT) expression in differentiated HL-60 cells: regulatory mechanisms. Br J Cancer 80: 1156-1161, 1999.

45. Bachand F, Triki I and Autexier C: Human telomerase RNAprotein interactions. Nucleic Acids Res 29: 3385-3393, 2001.
46. Ford LP, Suh JM, Wright WE and Shay JW: Heterogeneous nuclear ribonucleoproteins $\mathrm{C} 1$ and $\mathrm{C} 2$ associate with the RNA component of human telomerase. Mol Cell Biol 20: 9084-9091, 2000 .

47. Yi X, Shay JW and Wright WE: Quantitation of telomerase components and hTERT mRNA splicing patterns in immortal human cells. Nucleic Acids Res 29: 4818-4823, 2001.

48. Ozawa T, Gryaznov SM, Hu LJ, et al: Antitumor effects of specific telomerase inhibitor GRN163 in human glioblastoma xenografts. Neurooncology 6: 218-226, 2004.

49. Takeuchi H, Kanzawa T, Kondo Y, Komata T, Hirohata S, Kyo S and Kondo S: Combination of caspase transfer using the human telomerase reverse transcriptase promoter and conventional therapies for malignant glioma cells. Int J Oncol 25: 57-63, 2004.

50. Strakova N, Ehrmann J, Dzubak P, Bouchal J and Kolar Z: The synthetic ligand of peroxisome proliferator-activated receptorgamma ciglitazone affects human glioblastoma cell lines. J Pharmacol Exp Ther 309: 1239-1247, 2004. 